\title{
Electoral Results: Can Entropy be a Measure of the Population Dissatisfaction?
}

\author{
Paulo Ferreira (Correspondence author) \\ Center for Advanced Studies in Management and Economics of the University of Évora \\ University of Évora, CEFAGE-UE \\ Largo dos Colegiais, 27000 Évora, Portugal \\ E-mail: pjsf@uevora.pt \\ Andreia Dionísio \\ Center for Advanced Studies in Management and Economics of the University of Évora \\ University of Évora, CEFAGE-UE \\ Largo dos Colegiais, 27000 Évora, Portugal \\ E-mail: andreia@uevora.pt
}

Received: October 21, $2011 \quad$ Accepted: November 10, $2011 \quad$ Published: February16, 2012

doi:10.5539/ijbm.v7n4p2

URL: http://dx.doi.org/10.5539/ijbm.v7n4p2

\begin{abstract}
This paper intends to explore the utilization of entropy through politics and election results, a slightly explored area. It generalizes the interpretation of entropy, considering it a measure of dissatisfaction and disillusion of populations in what concerns to politics. We can detect and analyze some phenomena, such as the increase of abstention in a country, a consequence of the dissatisfaction of the population and their alienation related to politics. New political parties can emerge due to the discontentment of the populations, leading to a larger division of votes and to the increase of the entropy (as a result of the discontentment and uncertainty of the electors). Absolute majorities imply less dispersion of votes and are a synonym of a higher confidence in a particular party, reducing entropy. Electoral results can also be influenced by particular phenomena, such as the terrorist attacks on the eve of the two last elections in Spain. These attacks had a great influence on the affluence to the polls, as well as on the levels of entropy.
\end{abstract}

Keywords: Entropy, Electoral results, Satisfaction and dissatisfaction of the population

\section{Introduction}

Entropy is a measure of information and uncertainty which has been recently used in different areas, besides its original utilization in physics. Economics is one of the areas where the number of papers using entropy increased substantially in the last few years. This is due to its interest and to the similarities between both research areas, although this connection is not so evident at first sight. See, for example, Golan et al. (1996), Maasoumi (1993), Darbellay and Wuertz (2000) or Dionísio et al. (2006).

But entropy is not only used in economics. Bailey $(1990 ; 1993)$ introduces the concept of Social Entropy Theory, applying the concept of entropy to Sociology. Furthermore, Chen (2003) uses entropy in a psychological theory that affects the behavior of agents acting in financial markets.

The concept of entropy has also been used to study elections. Gill (2005) uses entropy as a measure of uncertainty trying to explain the voting decision of those electors who effectively vote. Considering the "Contract with America", a document of the Republican Party in the 1994 USA elections, to clarify American's opinions, Gill (2005) analyses if such phenomena had changed uncertainty levels of the electors. He concluded that uncertainty is important in their decisions. Earlier, Kirchgässner and Schimmelpfennig (1992) used entropy as a measure of closeness of results. They concluded that entropy can be positively correlated with electoral participation. However, these authors used only two countries (UK and Germany). Their conclusions, in our opinion, cannot be extended for all the European countries.

Furthermore, Antweiler (2007) uses maximum entropy to analyze migration votes in two consecutive elections, 
and analyze also which electors changed their vote between two consecutive elections.

Our paper intends to explore the utilization of entropy through politics and through election results, but with different objectives. It generalizes the interpretation of entropy, considering it a measure of dissatisfaction and disillusion of populations in what concerns to politics, using the data of the legislative elections. We can detect and analyze some phenomena, such as the increase of abstention in a country, a consequence of the dissatisfaction of population and their alienation related to politics. New political parties can emerge due to the discontentment of the populations, leading to a larger division of votes and to the increase of the entropy (as a result of the discontentment and uncertainty of the electors).

Electoral results can also be influenced by particular phenomena, such as the terrorist attacks on the eve of the two last elections in Spain. These attacks had a great influence on the affluence to the polls, as well as on the levels of entropy. The results can also be influenced by the date of the election: for example, elections in the summer are more affected by the abstention. We can also establish a connection between the results of the elections with unpopular governmental socioeconomics policies or even with the economical performance of a country. We also try to associate these kinds of phenomena one with another, as well as with the concept of entropy. We aim yet to analyze the reality of different European countries.

This paper is organized as follows: Section 2 explains the concept of entropy and how this measure can be related with electoral abstention. It is also presented the estimation method for entropy used in this research. Section 3 presents the data used in this paper, while section 4 shows the results of the connection between entropy and abstention. In section 5, we compare entropy with other measures of variation and concentration, such as variance and the Herfindahl concentration index. Section 6 presents other possible results which could be related with the theme: the relationship between abstention and GDP growth, and how abstention could be explained by unexpected facts. In section 7 we present our conclusions.

\section{Entropy and electoral abstention}

Entropy is a concept used in thermodynamics, related with the degree of disorder of a state, a concept created by Clausius in 1865. Later, in 1877, Ludwig Boltzmann defined a probabilistic method to measure entropy. In the twentieth century, von Neumann and Shannon worked this concept. In the study considered the base of the Information Theory, Shannon (1948) defines entropy as:

$$
H(X)=-\sum p_{i} \ln p_{i}
$$

where $p_{i}$ is the probability of the event $i$.

Shannon's entropy is a measure of uncertainty which is non-negative (Note 1). Zero is its minimum value, and it is only verified when exist one single event, when there is certainty. The maximum entropy value is verified when the distribution is uniform $\left(p_{i}=1 / n_{i}\right)$. Entropy measures total uncertainty of an unknown probability distribution. In the scope of Information Theory, Shannon (1948) uses entropy as a measure of the amount of information transmitted by a message. Entropy can also be seen as a measure of randomness of a system.

This measure can also be interpreted as a measure of surprise of a result: the lower the probability of an event, the greater the surprise of that event to occur. The value of $-\ln p_{i}$ exemplifies that surprise, because it is greater when the probability is lower. So, entropy could be identified as the average of how much a person should be surprised by the occurrence of an event. Moreover, when the uncertainty increases, the greater is the surprise of occurrence of an event increases as well (Dionísio et al. 2006).

Entropy for discrete distributions take its minimum when there is certainty about an event (i.e. $p_{i}=1$ and $\Sigma_{i=2}^{n}=0$ ). In what concerns to elections, it should occur if all electors vote in the same party (or candidate). The maximum entropy value will occur when the distribution of the probability is uniform. In what concerns to elections it means that all parties (or candidates) have the same number of votes.

In this research, entropy is used with discrete distributions, in order to analyze the evolution of electoral results. Besides its interpretation as uncertainty, entropy is interpreted in this paper as a measure of dissatisfaction of the electors. We do not have probabilities to estimate entropy in what concerns to the results of the elections. However, the data of the elections are relative frequencies, which verify some of the main properties of probabilities: $p_{i}>0$ and $\sum p_{i}=1$.

So, the estimation of entropy is done with the proportions of votes of each party. Suppose that in a given election there are three parties, with the following vector of the proportions of votes: $\{0.5 ; 0.3 ; 0.2\}$. In this case, the estimation of entropy following equation 1, would take the value of 1.0297. Since the number of parties in the elections of several countries is different, the relative entropy is calculated: entropy divided by its maximum 
value. Entropy takes its maximum value when the distribution is uniform. Considering the same election, having three parties, the proportions of votes would be $\{1 / 3 ; 1 / 3 ; 1 / 3\}$. So, entropy would take its maximum value, with 1.0986 , and relative entropy would be 0.9372 .

There are several studies trying to explain the reason why some electors vote and others abstain. Downs (1957), in a pioneer work in this research area, identifies the voting decision with the greater benefit for the elector, when compared with the voting cost, in a decision similar to economic agents as a consumer. This analyzes have been criticized because it can't explain all that's behind the voting decision of the electors. This happens because there are other motivations, such as the feeling of the civic duty, in the act of voting. Besides this, the decision of voting can also be related with an investment decision, expecting future benefits, rather than with a consumption one (see, for example, Riker and Ordeshook 1968; Palfrey and Rosenthal 1983).

Other explanations for the voting decision are given through models which use a spatial approach to explain that decision: the greater the proximity between elector's and candidates' opinion, the greater the probability of an elector to vote in that candidate. Ferejohn and Fiorina (1974), Enelow and Hinich (1981), Paldam and Skott (1995), Kirchgässner (2003) and Gill (2005) used this kind of analysis.

The purpose of this paper is not to create a model of the decision to vote or to abstain, but as referred, to relate abstention with entropy, in order to conclude if entropy can be seen as a measure of dissatisfaction. The main question is: should it be possible to use entropy as a measure of the dissatisfaction of the electors?

In the particular case of the USA elections, Gill (2005) refers that there is a great complexity in the elections. This is due to the vague speech of the candidates, what causes some uncertainty in the electors. Besides this, the lack of knowledge of the electoral programs and the lack of time of the electors to analyze them can contribute to that uncertainty. The existence of asymmetric information, according to the same author, can conduct some electors to think that the best alternative is not to vote (see also Enelow and Hinich 1981; Feddersen and Pesendorfer 1999). So, and according to Gill (2005), if some electors vote and others do not, this is due to the different levels of uncertainty of the electors.

At an aggregate level, Blais et al. (2003) try to identify what are the factors that influence the electoral participation, covering 151 elections in 61 different countries. GDP per capita is one of the variables, showing a positive impact in the participation. The dimension of the population also contributes to the turnout, but in a negative manner: more populated countries have less participation in elections. The electoral systems that allow votation through alternative ways (mail, in advance or by proxy) and those which have compulsory vote (penalizing those who do not vote) present also more relative participation in the elections. Feddersen and Pesendorfer (1999) also identify the reduction of voting barriers as a potential variable which could raise the turnout. Furthermore, in the specific context of the American elections, Abramson and Aldrich (1982) found evidence that, even with an easier registration and with a higher education, the turnout in USA, between 1966 and 1980 decreased. Some other factors, such as dissatisfaction and the non identification with the political parties explain that phenomenon (Abramson and Aldrich 1982).

About the personal decision of to vote or to abstain, the motives are obviously different. Paldam and Skott (1995) and Kirchgässner (2003) refer that according to the electors' point of view political parties would getter more votes if they would present significant differences amongst themselves. So, one possible explanation for abstention is that the solutions presented by the political parties are similar and have no distinctive quality. This can be seen as a synonymous of the dissatisfaction of the electors. Or, in the other hand, that political parties present promises that they successively do not fulfill. Santo (2005) cites Georges Vedel (Note 2) affirming that one possible reason to the increase of abstention, in the case of France, is the depolitization, which can also be interpreted as a signal of the dissatisfaction of the population. Citing Freire and Magalhães (Note 3), Santo (2005) refers that abstention could be understood as a temporary attitude of dissatisfaction in what concerns to the political system as well as to the lack of confidence (Note 4). The lack of confidence and depolitization, associated with the weakening of the identification of the party, had been pointed by Abramson and Aldrich (1982) as possible explanations for the decrease of the turnout, in the specific case of USA. Another reason for the increase of abstention, pointed by the same authors, is the weakening of the beliefs in what concerns to the governmental responsiveness.

Note for example, the particular case of Portugal. Since the first elections in 1974 to the last ones in 2005, the level of abstention in Portugal presents a growing trend, which worries the political class and that can be interpreted as an indicator of the lack of credibility of the population. The lack of confidence in the political system is also seen as a problem in Portugal, Vargas (2002).

Based on these arguments we try to evaluate entropy as a measure of dissatisfaction of the political system in 
general. So, we think that is possible to analyze entropy as a measure of dissatisfaction, and its connection with abstention (see, for example, Santo 2005; Abramson and Aldrich 1982).

\section{Data}

Abstention is a phenomenon that occurs in all countries of the world and has been studied several times. This paper analyzes abstention in 14 European countries: Italy, Spain, Portugal, United Kingdom, the Netherlands, Germany, France, Norway, Sweden, Finland, Switzerland, Austria, Ireland and Denmark (Note 5). We chose these countries, because they presented data of several elections.

The study starts with the elections after II World War. This war became a turning point in the world history and from this point on data is more frequent. Austria, Finland, France, Norway, United Kingdom and Denmark were the first analyzed countries that had elections in post-II World War, in 1945; followed by the Netherlands in 1946; in 1947 elections took place for the first time in Switzerland, followed by Italy, Sweden and Ireland in 1948 and by Germany in 1949. In Portugal and in Spain the first free elections were, respectively, in 1974, 1975 and 1977. Table 1 indicates the first and the last year of the analysis, as well as the number of elections in each country. It is also indicated the source of the data for each country, usually sites of official pages of elections in each country (Note 6). Only legislative elections were considered. According to Santo (2005), the level of abstention can influence the context of the election (national, regional, European, presidential, etc.). So it was necessary to choose similar elections for each country.

In what concerns to time evolution we observed that the levels of abstention increased in almost all of the countries studied (see Figure 1). But this growing trend is not only verified in Spain, Norway and Denmark. In the cases of Germany and Sweden, abstention had decreased from the top to the middle of the sample. But from that time on, they have the same increasing path.

We used proportions of vote for the most voted parties to estimate discrete entropy. The number of parties used in each country, for the estimation of entropy, differs from country to country but, in the same country, the number of parties is always the same. To compare different countries and since entropy is sensitive in relation to the number of categories (parties) used in the analysis, it was calculated the relative entropy given by:

$$
H R=H / H M
$$

where HR is the relative entropy, $H$ the Shannon entropy and HM the maximum value for entropy.

The criterion used to choose the number of categories in each country is related with the number of parties most voted, in the first considered election. The purpose was that, at the beginning of the sample, the proportion of the category "Others" shouldn't exceed 10\%. It allows us to see, for example, the relevance and the evolution of this category. An increase in its value means that we have a greater dispersion on votes, being a clear indicator of the global uncertainty felt by the electors in what concerns to their political opinions, which will increase entropy. While there are countries where this category decreased (the case of Spain, that could be related with the particular event of terrorist attacks in the days before the elections in 2004 and 2008), in other countries that category is much more relevant. Excluding the cases of Germany, Spain and Portugal, all the other countries show a trend, more or less evident, of the increase in that category, in spite of the cases of Italy, Switzerland and Denmark where that value had decreased in the last elections. Figure 2 shows the behavior of the category "Others" of the different countries.

\section{Results}

Entropy is often used as a measure of uncertainty. In this paper we try to use it to analyze electoral processes, interpreting it as a measure of uncertainty of electors for politics in general. We think that entropy could be considered as a measure of dissatisfaction and disillusion in what concerns to politics.

Moreover, the dissatisfaction of the electors is caused, according to some authors, by the weakening of the interest for politics. This has consequences on the decreasing of the turnout, increasing abstention. So, entropy should be positively correlated with abstention. This means that, the greater the dissatisfaction of electors, the higher the values of the abstention (see, for example, Santo 2005; Abramson and Aldrich 1982). Individual results, for each of the fourteen countries analyzed, can be seen in Table 2. These values refer to the correlation between relative entropy and abstention, in each country.

After analyzing all of the countries in this database, we could verify that only four of them have different correlation coefficients from the expected: Portugal, France, Finland and Denmark. Of these countries, only the French case is significant at 5\% level. The Portuguese coefficient, although taking a relatively high value (even greater in absolute value when compared with the French coefficient), is not statistically significant at $5 \%$. In the 
Portuguese case, this could happen due to the fact that electoral files are often out of date. The case of France could be related with historical issues, especially with the fact that French population usually shows their dissatisfaction whit great manifestations like general strikes. In the case of Denmark, one possible explanation could be the relative stability of the abstention that could be seen as a sign of non-dissatisfaction of electors.

Among the countries that present positive coefficients, more than a half is significant: Italy, United Kingdom and Norway, at 5\% level and Germany, Switzerland, Austria and Ireland at 1\% level. Our results show relative support for the hypothesis formulated: abstention is related with uncertainty and dissatisfaction of the electors and politicians should be worried with the increasing trend of the abstention. This dissatisfaction can be related with different issues, such as de lack of credibility of parties/politicians or even the lack of preoccupation of citizens with politics because they do not believe in the political system. Considering that any country has a sample greater than twenty elections, results can be considered encouraging.

We calculated also the Kendall test. This is a non-parametric way to test correlation between variables, based on the rank correlation (in spite of value correlation). As we can see in the third column of Table 2, results are similar.

If the small dimension of the samples is seen as a problem in some countries, it is interesting to verify what happens if we aggregate data from different countries, making just one sample. To compare international data, we used two relative measures and calculated the correlation between the relative entropy and the abstention per capita (Note 7).

The sample recovered has a total of 241 elections. Estimating the correlation coefficient between relative entropy and the respective level of abstention per capita, the observed value is 0.3120 , which is statistically significant. We can conclude that, although results have weak support for individual analysis, when aggregated data are considered the relationship is significant.

\section{Comparing different measures}

Besides entropy, there are other measures traditionally used to measure uncertainty, variability and concentration. Variance is the most common measure of variability, which can be also interpreted as a measure of uncertainty. Another index widely used to measure concentration drifts from industrial economics is the Herfindahl concentration index. Once again, because different countries use different numbers of categories (parties), it was calculated the relative Herfindahl index.

We calculated correlations between the following variables: relative entropy (HR), relative variance (VARR), relative Herfindahl index (HHR) and abstention per capita (Abstpc). Results can be seen at Table 3 .

A strong and significant correlation between those three measures can be verified. The relationship between relative entropy and relative variance takes a positive value of 0.6346 . Effectively, these are measures have the same intention: both can be considered as uncertainty and variability measures. Comparing the performance of both measures with abstention (measured per capita), relative entropy has stronger results: in spite of the fact that both variables present a significant correlation, significance is stronger in the relative entropy.

When compared with Herfindahl index (HHR), entropy presents a significant correlation. As expected, that correlation is negative: while entropy is a measure of uncertainty and dispersion, Herfindahl index is a measure of concentration. Once again as expected, the correlation between HHR and abstention per capita is negative. In absolute terms, relative entropy shows stronger correlation with abstention per capita, when compared with relative variance.

\section{Other possible facts that can be analyzed}

Besides the connection between abstention and entropy, this research analyses other related issues. In this section, we analyze the possible relationship between abstention and the growth of the GDP, the effect of specific and unexpected events during the electoral period and the relationship between opinion polls and uncertainty of the electors (Note 8).

\subsection{Abstention and GDP growth}

Some authors, like Blais et al. (2003), refer that the turnout can be positively related with the level of growth in a country. In this paper we make an analysis of this connection, evaluating the relation between growth rate and abstention and the relation between growth rate and abstention per capita (Note 9). The correlation between growth rate, abstention and abstention per capita is shown in the Table 4. According to the literature, the expected connection between these variables is a negative one: higher levels of growth should make abstention lower, because countries with greater growth rates should have more informed and interested citizens in politics 
(Blais et al. 2003).

In our case, results are not the expected. Most of countries analyzed reveal a negative connection between abstention and GDP growth, although, only four of them have statistical significance: Italy, Austria, Denmark and Switzerland. Four countries present positive correlation levels (Spain, United Kingdom, Sweden and Ireland), but none is statistically significant, using the usual levels of significance.

Using the same analysis for the abstention per capita, the results are somehow different. Only five countries show positive correlation (Spain, United Kingdom, France Sweden and Ireland), but none is significant. The remaining countries show the expected correlation and four of them are significant: Denmark, Austria and Italy with $5 \%$ of significance, and Switzerland, with $2 \%$.

These results may be explained by the reduced number of observations in this case, when compared with previous samples, once data used to calculate growth rates, sourced by IFM, is less numerous. In the other hand, and perhaps more important, is the fact that in this study we only use countries with relatively high degrees of economic development. The study of Blais et al. (2003) uses a heterogeneous group of 61 countries from different continents. For those countries, GDP could be relevant. In this case, this is not probably the most important variable.

\subsection{Specific events: an example}

It is usual to say that some events have the ability to change the results of the elections. Is this true? At least in the case of Spain it seems to be. The electoral campaign in 2004 was coming to end, with opinion polls indicating a victory for Popular Party (PP), when the terrorist attacks of 11 March in Madrid happened. The PP government blamed ETA but in fact they were conducted by Islamic groups. After this, the electoral results were completely different from the opinion polls, giving a clear victory for the Socialist Party (PSOE).

Gassebner et al. (2008) based their study in this particular phenomenon. Based on Barro's (1973) and Ferejohn's (1986) theoretical approaches, and on the hypothesis that "Terrorism increases the probability that the incumbent government is replaced at the next election", they concluded that terrorist attacks and, in particular, their severity, had an effective impact in the decision of the electors in changing the government. This happens because national security is considered an extremely important public service and severe terrorist attacks are considered failures of the governments.

In the particular case of the Spanish elections in 2004, the electors showed his certainty by punishing PP, at the same time the turnout increased. How can entropy be used to analyze this particular event? As previously referred, entropy was used in this paper as a measure of uncertainty and can be interpreted as a measure of dissatisfaction in what concerns to politics in general.

Before the attacks, there was no reason to think that the elections would not occur as usually. On the last day that opinion polls were published in Spain, four different organizations presented their results (IPSOS-ECO, SIGMA-DOS, Instituto Opina and Demoscopia). Only the first one pointed PSOE as the winning party. The results of the polls, in what concerns to entropy, were $\{1.2136 ; 1.1871 ; 1.2182 ; 1.1993\}$ (Note 10). The entropy of the electoral results was 1.1787. It confirms that entropy decreased, in all polls.

Besides this, a test was made to detect if the results of these polls were equal to the result of the election. Since the entropy of the polls has a non-normal distribution, we used a non-parametric test. Because we have independent samples, we chose the Mann-Whitney $U$ test. This is a test to assess whether two samples of observations have the same distribution. With a p-value of 0,014 we reject the null hypothesis at the level of $5 \%$, meaning that the distribution of the polls is different from the effective result of that election.

What can we conclude? The electors were unhappy with what happened with the government party and mobilized to vote in PSOE. Can we ask the following question: isn't entropy being interpreted as a dissatisfaction indicator? Apparently yes, but as an indicator of the dissatisfaction related to politics in general. In this case, the reduction of entropy is due to the dissatisfaction with a particular party, or to the fact that uncertainty about the political parties was reduced.

\section{Conclusions}

The main goal of this research is to extend the use of entropy in elections. Being entropy a measure of uncertainty, we believed that it can be seen as a measure of the dissatisfaction of the electors in what concerns to politics in general (see, for example, Abramson and Aldrich 1982; Santo 2005). We evaluate the connection between several variables, expecting that the dissatisfaction of the electors would be higher, the turnout would be lower and, consequently, abstention would be higher. 
Based on this assumption, we calculated the correlation between abstention and entropy and obtained, in 10 of the 14 countries of the sample, positive correlation coefficients, as our assumption indicates. Only Portugal, Finland, Denmark and France have negative coefficients, and only the last one is significant. When this coefficient is calculated with grouped data, the result is statistically significant, probably because of the increase of our sample.

We also compared three different measures normally used to evaluate dispersion and concentration: entropy, variance and Herfindahl index, all in relative terms. The first two measures presented a close connection. When compared with abstention, both in absolute and per capita terms, relative entropy has stronger results. Relative entropy shows an inverse relation, as expected, with the Herfindahl index. However, both measures present similar qualitative results when compared with abstention: higher abstention can be seen as dissatisfaction of the populations but also has a positive correlation with entropy.

Finally, other facts were identified. According to some authors, it is expected that abstention should be negatively correlated with the GDP. Calculating the correlation between abstention and the growth rate, grouped results present a positive correlation, contrary to the expected, but statistically non-significant. However, if we consider countries individually, the results point to an expected correlation statistically significant. This can be explained by the relative homogeneity of countries, in what concerns to economic development.

Entropy could also be used, in this context, to try to explain some events. That's what happened with Spain, where the terrorist attacks on the 11 March 2004 changed the vote intention of the electors. Furthermore, the result is significantly different from these of the surveys. Once the opinion of the polls in general does not differ from the average of election results, it is concluded that entropy can also explain some specific events occurred during the electoral period.

\section{Acknowledgement}

The authors thank the financial support provided by Fundação para a Ciência e Tecnologia (FCT) under the grants $n^{\circ}$ PTDC/GES/70529/2006 and $n^{\circ}$ PTDC/GES/73418/2006.

\section{References}

Abramson, P., \& Aldrich. J. (1982). The Decline of Electoral Participation in America. The American Political Science Review, 76, 502-521. http://dx.doi.org/10.2307/1963728

Antweiler, W. (2007). Estimating Voter Migration in Canada Using Generalized Maximum Entropy. Electoral Studies, 26, 756-771. http://dx.doi.org/10.1016/j.electstud.2007.07.005

Bailey, K. (1983). Sociological Entropy Theory: Toward a Statistical and Verbal Congruence. Quality and Quantity, 18, 113-133, http://dx.doi.org/10.1007/BF00221453

Bailey, K. (1990). Social Entropy Theory. State University of New York (SUNY) Press.

Bailey, K. (1993). Social entropy theory: an application of nonequilibrium thermodynamics in human ecology. Advances in Human Ecology, 2, 133-161.

Barro, R. (1973). The control of politicians: an economic model. Public Choice, 14, 19-42. http://dx.doi.org/10.1007/BF01718440

Blais, A., Massicotte. L., \& Dobrzynska. A. (2003). Why is Turnout Higher in Some Countries than in Others? Elections Canada working paper.

Chen, J. (2003). An Entropy Theory of Psychology and its Implication to Behavioral Finance. Financiële Studievereniging Rotterdam Forum, 6, 26- 31.

Darbellay, G., \& Wuertz.D. (2000). The Entropy as a Tool for Analysing Statistical Dependence's in Financial Time Series. Physica A, 287, 429-439. http://dx.doi.org/10.1016/S0378-4371(00)00382-4

Dionísio, A., Menezes.R., \& Mendes. D. (2006). An econophysics approach to analyze uncertainty in financial markets: an application to the Portuguese stock market. The European Physical Journal B, 50, 161-164. http://dx.doi.org/10.1140/epjb/e2006-00113-2

Downs, A. (1957). An Economic Theory of Democracy. New York, Harper and Row.

Enelow, J., \& Hinich. M. (1981). A New Approach to Voter Uncertainty in the Downsian Spatial Model. American Journal of Political Science, 25, 483-493. http://dx.doi.org/10.2307/2110815

Feddersen, T., \& Pesendorfer. W. (1999). Abstention in Elections with Asymmetric Information and Diverse Preferences. American Political Science Review, 93, 381-398. http://dx.doi.org/10.2307/2585402 
Ferejohn, J. (1984). Incumbent performance and electoral control. Public Choice, 50, 5-25. http://dx.doi.org/10.1007/BF00124924

Ferejohn, J., \& Fiorina. M. (1974). The paradox of not voting: a decision theoretic analysis. American Political Science Review, 68, 525-536. http://dx.doi.org/10.2307/1959502

Gassebner, M., Jong-A-Pin R., \& Mierau. J. (2008). Terrorism and electoral accountability: One strike, you're out!. Economics Letters, 100, 126-129. http://dx.doi.org/10.1016/j.econlet.2007.12.011

Gill, J. (2005). An entropy measure of uncertainty in vote choice. Electoral Studies, 24, 371-392. http://dx.doi.org/10.1016/j.electstud.2004.10.009

Golan, A., Judge. G., \& Miller. D. (1996). Maximum Entropy Econometrics - Robust Estimation with Limited Data. Wiley.

Kirchgässner G. (2003). Abstention because of Indifference and Alienation, and Its Consequences for Party Competition: A Simple Psychological Model. University of St. Gallen discussion paper 2003-12. http://dx.doi.org/10.2139/ssrn.401882

Kirchgässner, G., \& Schimmelpfennig. J. (1992). Closeness counts if it matter for electoral victory: Some empirical results for the United Kingdom and the Federal Republic of Germany. Public Choice, 73, 283-299. http://dx.doi.org/10.1007/BF00140923

Maasoumi, E. (1993). A Compendium to Information Theory in Economics and Econometrics. Econometric Reviews, 12(2), 137-181. http://dx.doi.org/10.1080/07474939308800260

Paldam, M., \& Skott. P. (1995). A rational-voter explanation of the cost of ruling. Public Choice, 83, 159-172. http://dx.doi.org/10.1007/BF01047690

Palfrey, T., \& Rosenthal. H. (1983). A strategic calculus of voting. Public Choice, 41, 7-53. http://dx.doi.org/10.1007/BF00124048

Riker, W., \& Ordeshook. P. (1968). A Theory of the Calculus of Voting. American Political Science Review, 62, 25-42. http://dx.doi.org/10.2307/1953324

Santo, P. (2005). Um contributo acerca da abstenção eleitoral em revista. Sociologia, Problemas e Práticas, 47, $147-150$.

Shannon, C.E. (1948). A Mathematical Theory of Communication. Bell Systems Tech., 27, 379-423, 623-656.

Strömberg, D. (2004). Radio's Impact on Public Spending. The Quarterly Journal of Economics, 119, 189-221. http://dx.doi.org/10.1162/003355304772839560

Vargas, A. (2002). Governabilidade e governação: novas formas de legitimação Portugal. VII Congresso Internacional del CLAD sobre La Reforma del Estado y de la Administración Pública, Portugal(October 2002).

\section{Notes}

Note 1. Equation 1 refers to entropy of discrete distributions. Entropy of continuous distributions was also defined by Shannon (1948). It presents some different properties but it is not referred in this paper because it will not be used.

Note 2. Vedel, G. (1962). La Dépolitisation: Mythe ou Réalité?, Paris, Libraire Armand Colin.

Note 3. Freire, A., Magalhães, P. (2002). A Abstenção Eleitoral em Portugal, Lisboa, Instituto de Ciências Sociais da Universidade de Lisboa.

Note 4. Bailey (1983) refers that maximum entropy is the "system death" (p. 114). The increase of entropy, in the context of elections and interpreted as social dissatisfaction shouldn't mean the "death of democracy" but should be analyzed by politicians as a problem, like the increase of the abstention.

Note 5. In our research we recovered data of Belgium and Greece. However, these countries have a compulsory vote system, so we didn't use them in this analysis, because the reality of the abstention is different when compared with other countries.

Note 6. For some elections, in the absence of information about abstention, data was recovered from www.idea.int/vt/.

Note 7. Abstention per capita represents the value of percentage of abstention of million inhabitants. A similar indicator to this is used in Strömberg (2004).

Note 8 . We tried to use other variables, like unemployment rate, but we would lose several observations, because 
there were no available data for the same years.

Note 9. The growth rate used is the average growth between two consecutive elections.

Note 10. In this case, entropy was estimated transforming the proportion of the number of deputies indicated by the polls. As the proportion of deputies is not equal to the proportion of votes, to compare the results of the polls with the electoral result, the entropy of this election was also estimated with those data.

Table 1. Number of elections for each country

\begin{tabular}{|c|c|c|c|l|}
\hline Country & $1^{\text {st }}$ Election & Last Election & N. of elections & \multicolumn{1}{|c|}{ Source } \\
\hline Ita & 1948 & 2008 & 16 & elezionistorico.interno.it \\
\hline Spa & 1977 & 2008 & 10 & www.elecciones.mir.es \\
\hline Por & 1975 & 2009 & 13 & www.cne.pt \\
\hline UK & 1945 & 2005 & 17 & www.election.demon.co.uk \\
\hline Net & 1946 & 2006 & 19 & www.kiesraad.nl \\
\hline Ger & 1949 & 2009 & 17 & www.bundeswahlleiter.de \\
\hline Fra & 1945 & 2007 & 18 & www.interieur.gouv.fr \\
\hline Nor & 1945 & 2005 & 16 & www.regjeringen.no \\
\hline Swe & 1948 & 2006 & 19 & www.val.se \\
\hline Fin & 1945 & 2007 & 18 & statfin.stat.fi \\
\hline Swi & 1947 & 2007 & 16 & www.parties-and-elections.de \\
\hline Aut & 1945 & 2006 & 19 & www.bmi.gv.at \\
\hline Ire & 1948 & 2007 & 18 & electionsireland.org \\
\hline Den & 1945 & 2007 & 25 & www.ft.dk \\
\hline & & & & \\
\hline
\end{tabular}

Table 2. Individual results of correlation between entropy and abstention

\begin{tabular}{|c|c|c|}
\hline Country & Correlation between entropy and abstention & Kendall's test \\
\hline Ita & $0.5927^{*}$ & $0.367^{*}$ \\
\hline Spa & 0.2031 & 0.022 \\
\hline Por & -0.3968 & -0.231 \\
\hline UK & $0.5490^{*}$ & $0.376^{*}$ \\
\hline Net & 0.1884 & 0.181 \\
\hline Ger & $0.8404^{* *}$ & $0.657^{* *}$ \\
\hline Fra & $-0.5130^{*}$ & -0.294 \\
\hline Nor & $0.5160^{*}$ & 0.269 \\
\hline Swe & 0.0390 & -0.018 \\
\hline Fin & -0.0279 & -0.072 \\
\hline Swi & $0.6859^{* *}$ & $0.427^{*}$ \\
\hline Aut & $0.8397^{* *}$ & $0.335^{*}$ \\
\hline Ire & $0.7032^{* *}$ & $0.511^{*}$ \\
\hline Den & -0.3800 & -0.174 \\
\hline
\end{tabular}

Note: $* *$ significant at $1 \%$ level *significant at $5 \%$ level. 
Table 3. Comparison of different measures

\begin{tabular}{|c|c|c|c|c|}
\hline & HR & VARR & HHR & Abstpc \\
\hline HR & 1 & $0.6346^{* *}$ & $-0.9742^{*}$ & $0.3120^{* *}$ \\
\hline VARR & & 1 & $-0.5647^{* *}$ & $0.2639^{* *}$ \\
\hline HHR & & & 1 & $-0.2746^{* *}$ \\
\hline Abstpc & & & & 1 \\
\hline
\end{tabular}

Note: $* *$ significant at $1 \%$ level $*$ significant at $5 \%$ level.

Table 4. Individual results of correlations between growth and abstention and between growth and abstention per capita

\begin{tabular}{|c|c|c|c|}
\hline Country & $\begin{array}{c}\text { Correlation between GDP } \\
\text { growth and abstention }\end{array}$ & $\begin{array}{c}\text { Correlation between GDP growth and } \\
\text { abstention per capita }\end{array}$ & N \\
\hline Ita & $-0.7604^{*}$ & $-0.7449^{*}$ & 10 \\
\hline Spa & 0.3158 & 0.1312 & 9 \\
\hline Por & -0.4018 & -0.3682 & 11 \\
\hline UK & 0.1290 & 0.1524 & 15 \\
\hline Net & -0.1445 & -0.0782 & 15 \\
\hline Ger & -0.0645 & -0.0238 & 12 \\
\hline Fra & -0.2683 & 0.0362 & 14 \\
\hline Nor & -0.3453 & -0.2117 & 10 \\
\hline Swe & 0.3120 & 0.3698 & 17 \\
\hline Fin & -0.4250 & -0.4248 & 13 \\
\hline Swi & $-0.7429^{* *}$ & $-0.7316^{* *}$ & 15 \\
\hline Aut & -0.5604 & $-0.5544^{*}$ & 13 \\
\hline Ire & 0.4455 & 0.0448 & 17 \\
\hline Den & $-0.5555^{*}$ & $-0.5729^{*}$ & 16 \\
\hline
\end{tabular}

Note: **significant at $1 \%$ level *significant at $5 \%$ level. 


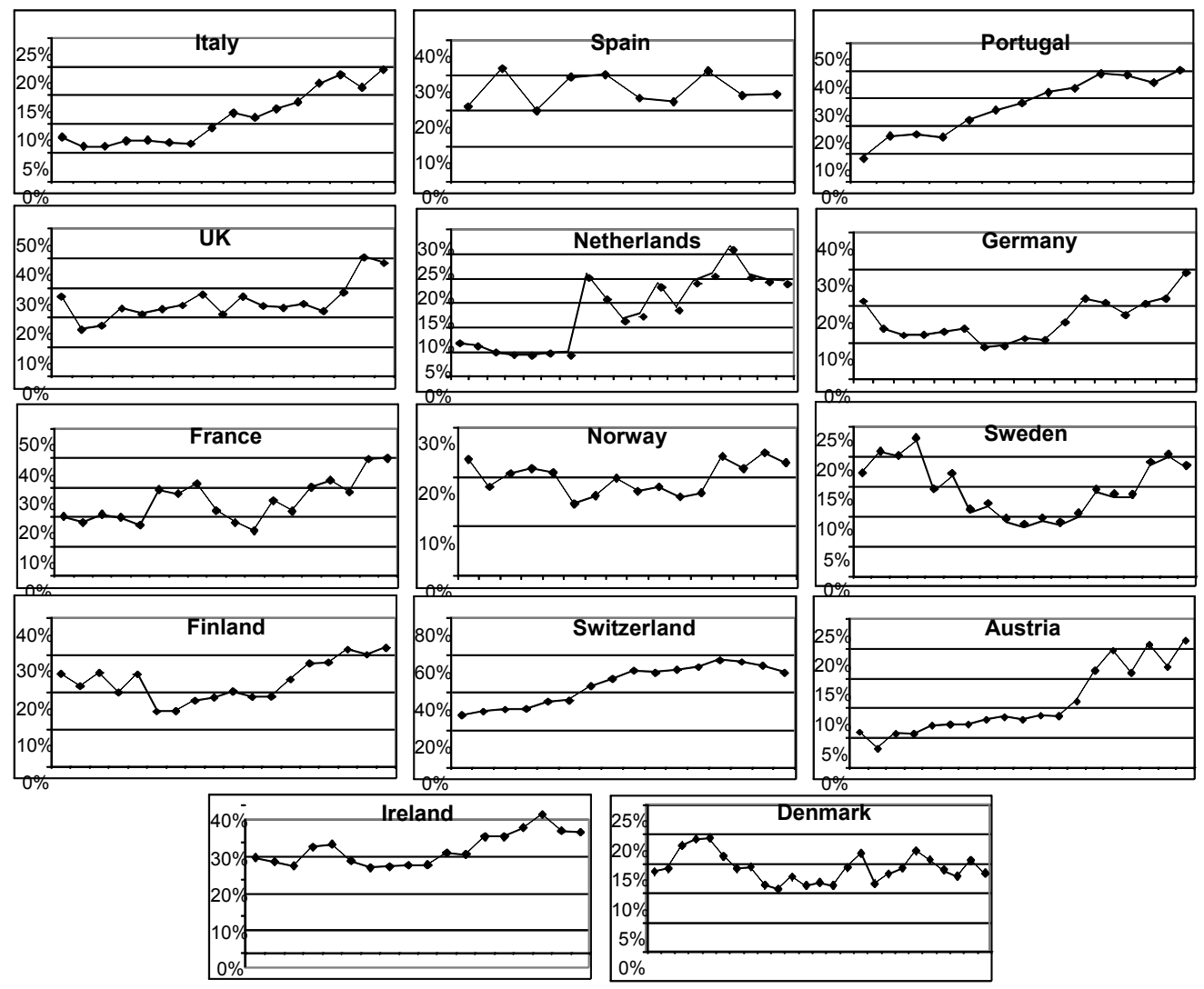

Figure 1. Evolution of abstention

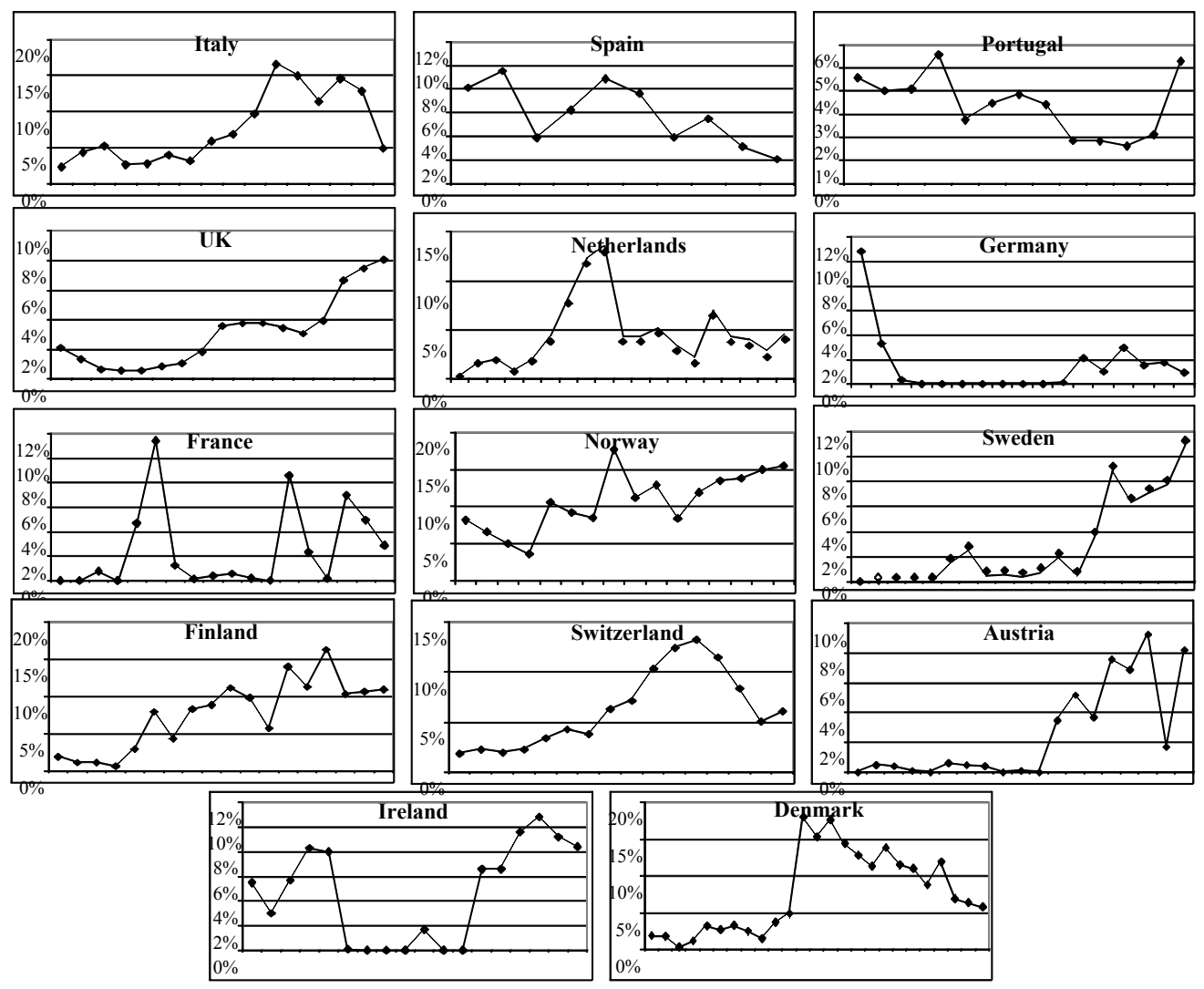

Figure 2. Evolution of the category "Others" 